Journal of Advanced Research in Fluid Mechanics and Thermal Sciences

\title{
The Sulphate Removal via Post Alkaline Treatment on Nanocrystalline Cellulose with Different Lignin Content Extracted from Kenaf Core
}

\author{
Fatimah Athiyah Sabaruddin ${ }^{1}$, Paridah Md Tahir ${ }^{1,{ }^{*}}$, Lee Seng Hua ${ }^{1}$, Lee Chuan $\mathrm{Li}^{1}$ \\ 1 Institute Tropical Forestry and Forest Product (INTROP), Universiti Putra Malaysia, Jalan Asam Jawa, 43400 Serdang, Selangor, Malaysia
}

\begin{tabular}{|c|c|}
\hline ARTICLE INFO & ABSTRACT \\
\hline $\begin{array}{l}\text { Keywords: } \\
\text { Cellulose; NCC; Lignin; Post Alkaline } \\
\text { Treatment; Thermal Properties }\end{array}$ & $\begin{array}{l}\text { The production of nanocrystalline cellulose (NCC) usually takes place through a series } \\
\text { of chemical processes like pulping, bleaching and acid hydrolysis process. The hydrolysis } \\
\text { processes using strong acid like } \mathrm{H}_{2} \mathrm{SO}_{4} \text { can help the } \mathrm{NCC} \text { to have a high degree of } \\
\text { crystallinity and imparts a negative surface charge to NCC. However, the application of } \\
\mathrm{H}_{2} \mathrm{SO}_{4} \text { leads to increment in dehydration reaction and lowered the NCC thermal } \\
\text { properties. Post alkaline treatment is the method that is commonly used to recover the } \\
\text { effect of } \mathrm{H}_{2} \mathrm{SO}_{4} \text { by neutralizing the acid using a strong base like sodium hydroxide } \\
\text { ( } \mathrm{NaOH} \text { ). On the other hand, the effect of lignin in fibres was able to help in improving } \\
\text { the thermal properties and extraction of lignin was seen involving an excessive number } \\
\text { of chemicals. The lignin part can remain in the pulp by controlling the bleaching process. } \\
\text { Therefore, in this study, NCC with different lignin content went through post alkaline } \\
\text { treatment to remove the remaining sulphate groups. The thermal analysis revealed } \\
\text { that the existence of lignin and removal of sulphate groups help to increase the thermal } \\
\text { stability of the NCC by shifting the degradation and melting temperature to the higher } \\
\text { value. }\end{array}$ \\
\hline
\end{tabular}

\section{Introduction}

The production of nanoscale cellulose materials has been reviewed comprehensively in the last decade as its application, especially as a reinforcing agent in composites materials for the novel application is relatively new thus attract the attention among the nanotechnology researchers. The properties of nanocellulose have surpassed cellulose in terms of its lightweight, high surface area, higher strength and stiffness which make it as an excellent reinforcing agent for bio-nanocomposites for different application [1].

Generally, can be extracted from wood, plants, bacteria and algae. The types of nanocellulose then can be comprised into three which are nanocrystalline cellulose (NCC), nanofibrillated cellulose (NFC) and bacterial cellulose (BC). The NCC and NFC can be extracted from natural sources like wood and plants which include pre-treatment process to break off the amorphous part of cellulose. The process starts with the pulping method to break the wood fibres by the chemical and mechanical

\footnotetext{
* Corresponding author.

E-mail address: parida@upm.edu.my

https://doi.org/10.37934/arfmts.84.1.1119
} 
process to produce wood microfibers [2]. The pulping methods can be comprised into many types includes soda, kraft, sulphite and organosolv. The main aim of pulping is to remove lignin in the fibres. The bleaching, on the other hand, is a treatment to further remove the lignin constituent. Other than removing the lignin, bleaching also helps to clean up the pulp from impurities and increase the brightness of the pulp $[3,4]$.

The types of nanocellulose then can be differentiated after this both process whether it is NCC or NFC. NFC is fibrils with length and width in micrometres and nanometre scales and produce via a mechanical method. Meanwhile, NCC usually produces via acid hydrolysis process that degrades the amorphous regions, yielding only highly crystalline nanoparticle and having a low aspect ratio [5]. The application of strong acid like sulphuric acid $\left(\mathrm{H}_{2} \mathrm{SO}_{4}\right)$, usually takes place during the production of NCC through acid hydrolysis process [6]. However, during the process, some uronic acid and sulphate ester groups were attached to the surface of NCC and increased its dehydration reaction which leads to the decrement of thermal properties [7]. Post alkaline treatment was reported as one of the methods to stabilize the effect of sulphuric acid by neutralizing the acid strong bases such as sodium hydroxide $(\mathrm{NaOH})[8,9]$

As mention earlier, the removal of lignin is very common especially in the production of nanocellulose. This is because lignin act as a natural binder between cellulose and hemicellulose and its existence might impede the isolation of fibres into individual fibrils [1]. However, the application lignin was recently reported to have the ability on enhancing its properties particularly in thermal stability [8-11]. As reported by Yang et al., [11] lignin contains full of aromatic rings with various branches and the activity of chemical bond in lignin covered an extremely wide range. The degradation of lignin can go within the range of $100-900{ }^{\circ} \mathrm{C}$ which explain its high thermal stability. Therefore, retaining lignin in NCC might help to increase its thermal properties.

Hence, in this study, the extraction of NCC was controlled by having different stages of bleaching to produce NCCS of different lignin content. The NCCs then were rinsed with strong bases, $\mathrm{NaOH}$ at the end of the hydrolysis process to remove the remaining sulphate. The removal of sulphate group via post alkaline treatment was expected to help in increasing the thermal properties of the NCC and its effect on physical, chemical and morphological of NCC were studied.

\section{Experimental Methods}

\subsection{Material}

Kenaf core fibres (Hibiscus cannibinus) in the form of chips supplied by Malaysian Palm Oil Board (MPOB), Kajang Selangor. The chemicals for pulping, bleaching, acid hydrolysis and alkaline treatment namely sodium hydroxide $(\mathrm{NaOH})$, anthraquinone $(\mathrm{AQ})$, hydrogen peroxide $\left(\mathrm{H}_{2} \mathrm{O}_{2}\right)$, sodium chlorite $\left(\mathrm{NaClO}_{2}\right)$, acid acetic $\left(\mathrm{CH}_{3} \mathrm{CO}_{2} \mathrm{H}\right)$, acetone and ethanol used for the pre-treatment process were provided by Sigma Aldrich, Germany and SYSTERM.

\subsection{Preparation of Nanocrystalline Cellulose of Different Lignin Content \\ 2.2.1 Pulping of kenaf core}

The pulping of kenaf core was carried out via soda -AQ pulping process. Kenaf core in the form of chips of $2 \mathrm{~cm}$ size was cooked with a total weight of $200 \mathrm{~g}$ in digester using $20 \%$ sodium hydroxide $(\mathrm{NaOH})$ and $0.1 \%$ anthraquinone (AQ). The fibres were cooked with a ratio of fibres and cooking liquid, $1: 10$ at the temperature of $170{ }^{\circ} \mathrm{C}$ and 90 minutes. 


\subsubsection{Preparation of unbleached and bleached kenaf core pulps}

At this stage, there are two types of pulp were produced; a) unbleached pulp and b) bleached pulp. The bleached kenaf core pulped underwent three stages of bleaching (D1, D2 and D3) until become completely white. The bleaching condition was listed in Table 1.

\section{Table 1}

The Bleaching conditions

\begin{tabular}{|c|c|c|c|}
\hline Bleaching stage & Chemical charge & Reaction time (min) & Temperature $\left({ }^{\circ} \mathrm{C}\right)$ \\
\hline $\mathrm{D}_{1}$ & $\begin{array}{l}\text { 2\% Sodium Chlorite } \\
3 \% \text { Acetic Acid }\end{array}$ & 120 & 70 \\
\hline Ep & $\begin{array}{l}1.5 \% \mathrm{NaOH} \\
1 \% \mathrm{H}_{2} \mathrm{O}_{2}\end{array}$ & 90 & 70 \\
\hline $\mathrm{D}_{2}$ & $\begin{array}{l}\text { 1.5\% Sodium Chlorite } \\
\text { 3\% Acetic Acid }\end{array}$ & 90 & 60 \\
\hline Ep & $\begin{array}{l}1.5 \% \mathrm{NaOH} \\
1 \% \mathrm{H}_{2} \mathrm{O}_{2}\end{array}$ & 90 & 60 \\
\hline$D_{3}$ & $\begin{array}{l}\text { 1.5\% Sodium Chlorite } \\
\text { 3\% Acetic Acid }\end{array}$ & 90 & 60 \\
\hline
\end{tabular}

\subsubsection{The acid hydrolysis process and post alkaline treatment}

Unbleached and bleached pulps were treated via acid hydrolysis process using $64 \%$ sulphuric acid at $45{ }^{\circ} \mathrm{C}$ to produce NCC. The NCC suspension was subjected to multiple centrifugations to remove the remaining acid in the suspensions. The suspensions then sonicated for 30 minutes and neutralized using drops of strong alkali $(\mathrm{NaOH})$ until the $\mathrm{pH}$ of the suspension turn to complete neutral. Then, the suspensions were freeze-dried and kept in a cool and dry place.

\subsection{Characterization of the Nanocrystalline Cellulose}

\subsubsection{Chemical analysis and kappa number}

Lignin percentage and kappa number were determine using unbleached and bleached kenaf core pulps before acid hydrolysis process. The lignin percentage was analysed according to TAPPI T222 om-02 standard. Whilst, the kappa number was determined according to TAPPI 236 om-99 standard.

\subsubsection{Fourier transform infrared (FTIR) analysis}

The bonding type between two or more atoms and the functional groups of the NCC was carried our using FTIR machine (Perkin Elmer Spectrum -100, Germany). The frequencies range was set to be within $500-4000 \mathrm{~cm}^{-1}$.

\subsubsection{X-Ray diffraction analysis (XRD)}

The crystallinity properties of the KC NCC at different lignin content were studied via XRD analysis. The tests were performed by XRD machine model D8 Advance (Bruker, UK). To calculate the crystallinity of the specimens, the crystallinity index was determined based on the reflected intensity data as reported by Segal. 
$\operatorname{CrI}(\%)=\frac{\mathrm{I}_{002}-\mathrm{I}_{\mathrm{am}}}{\mathrm{I}_{002}} \times 100$

\subsubsection{Thermal analysis}

The thermal composition and thermal stability of NCC at different lignin content and its nanocomposites were done using TGA/SDTA 851 (Mettler Toledo, Switzerland) thermogravimetric analyser. The range of the temperature tested was from 50 to $700{ }^{\circ} \mathrm{C}$ with a heating rate of $10{ }^{\circ} \mathrm{C} / \mathrm{min}$ under nitrogen atmosphere.

\section{Result and Discussion}

\subsection{Lignin Content of Unbleached and Bleached Kenaf Core Pulp}

The different level of extraction of kenaf core fibres can impart different chemical composition and physical properties. The lignin content of kenaf core pulps with and without bleaching process was determined through chemical analysis and kappa number test and the value was listed in Table 2. The percentage of lignin and kappa number for unbleached pulp (UB) shown almost $95 \%$ higher value as compared to the bleached pulp (B). This result explained the effectiveness of the bleaching process to remove the lignin. The application of $\mathrm{Na}_{2} \mathrm{ClO}_{2}$ and $\mathrm{CH}_{3} \mathrm{CO}_{2} \mathrm{H}$ on the first stage of bleaching help to partially withdraw the lignin and hemicellulose component in kenaf core fibre [13]. The process continues with $E_{p} D_{2}$, and $E_{p} D_{3}$ sequences until almost all lignin and hemicellulose component were extracted out. During the extraction, hydrogen peroxide used at Ep stage helps to remove the residual chlorite in the pulps and ease the removal of lignin whilst the upcoming $D$ stage help to remove the remainder hemicellulose and lignin $[13,144]$. Up to stage $D_{3}$, almost all lignin was extracted out indicate the effectiveness of removal of lignin during the bleaching process.

Table 2

The lignin percentage and kappa number of kenaf core pulps

\begin{tabular}{lll}
\hline Sample & Lignin (\%) & Kappa number \\
\hline Unbleached Pulp (UB) & 11.48 & 32.2 \\
Bleached Pulp (B) & 0.32 & 2.0 \\
\hline
\end{tabular}

\subsection{Fourier Transform Infrared (FTIR) Analysis}

The chemical properties of unbleached and bleached NCC after the alkaline treatment were analysed via FTIR analysis and the results were depicted in Figure 1. The graphs showed the FTIR peaks for unbleached and bleached NCC before and after the alkaline treatment where all peaks showed similar adsorption peaks at $3300-3330 \mathrm{~cm}-1$. However, the alkaline treated samples showed weaker intensities suggested neutralized NCC (NCC-UB (T) and NCC-B (T)) absorbed less moisture compared to those non-neutralized NCC (NCC-UB and NCC-B).

Other major adsorption peaks at $2895 \mathrm{~cm}^{-1}, 1438 \mathrm{~cm}^{-1}, 1323 \mathrm{~cm}^{-1}$ and $1023 \mathrm{~cm}^{-1}$ referring to $\mathrm{O}-\mathrm{H}$ stretching, $\mathrm{CH}_{2}$ vibrations, $\mathrm{CH}$ deformation and $\mathrm{C}-\mathrm{O}$ stretching vibration respectively, were seen to shift to higher frequencies with higher intensities after the alkaline treatment. This occurrence might be related to the removal of the remaining amorphous component in the NCC and increase the number of cellulose contents. Apart from that, low-intensity peak at $1090-1050 \mathrm{~cm}^{-1}$ were attributed to the existence of the sulphate group and were seen to disappear after the alkaline treatment. 


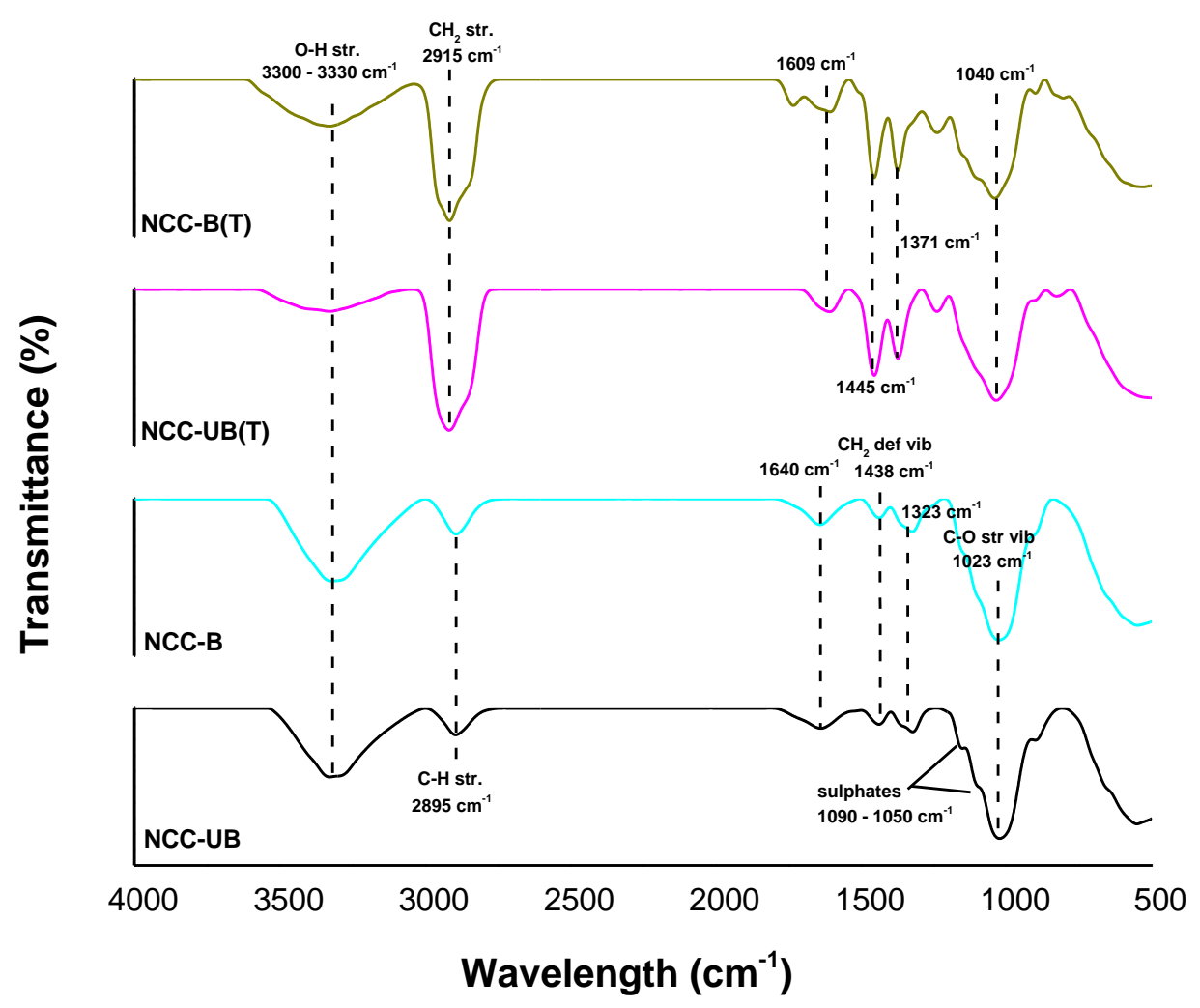

Fig. 1. The FTIR graph of unbleached and bleached NCC before and after alkaline treatment

\subsection{X-ray Diffraction (XRD) Analysis}

The XRD analysis of kenaf core NCC with and without bleaching process with different post alkaline conditions as depicted in Figure 2. The XRD graphs of all samples showed two important peaks at $18^{\circ}$ and $22.5^{\circ}$ correspond to cellulose I (220) plane and (110) crystallographic plane, respectively. However, the crystallinity index for all samples was showed mixed results.

The crystallinity index of the nanocelluloses was calculated according to Segal's empirical method by using values of (200) plane, $I_{c}$ and subtracting it to the minimum intensity of the peak at (110) plane, $I_{a m}$. This method was used to describe the relative amount of crystalline materials in fibre [1517]. The value of the crystallinity index is provided in Figure 2. The unbleached NCC (NCC-UB) showed an increment of crystallinity index after being bleached from $70.25 \%$ to $74.81 \%$. This result indicates the removal of amorphous materials including lignin and hemicellulose during the bleaching process considered the intensify cleavage of cellulose molecular chain within the amorphous region and increase the crystallinity of the bleached NCC (NCC-B). The hydrolysis process also helps to hydrolyse the fibre with the assistant of optimum time and acid concentration thus improve the crystallinity of the NCC [18].

Meanwhile, the crystallinity index for the post alkaline treated NCC was seen to decrease for both bleached and unbleached NCC. This occurrence is suggested due to the sudden interruption of strong bases during the washing process and retard the hydrolysation of cellulose chain and lowered the crystallinity of the treated NCC. 


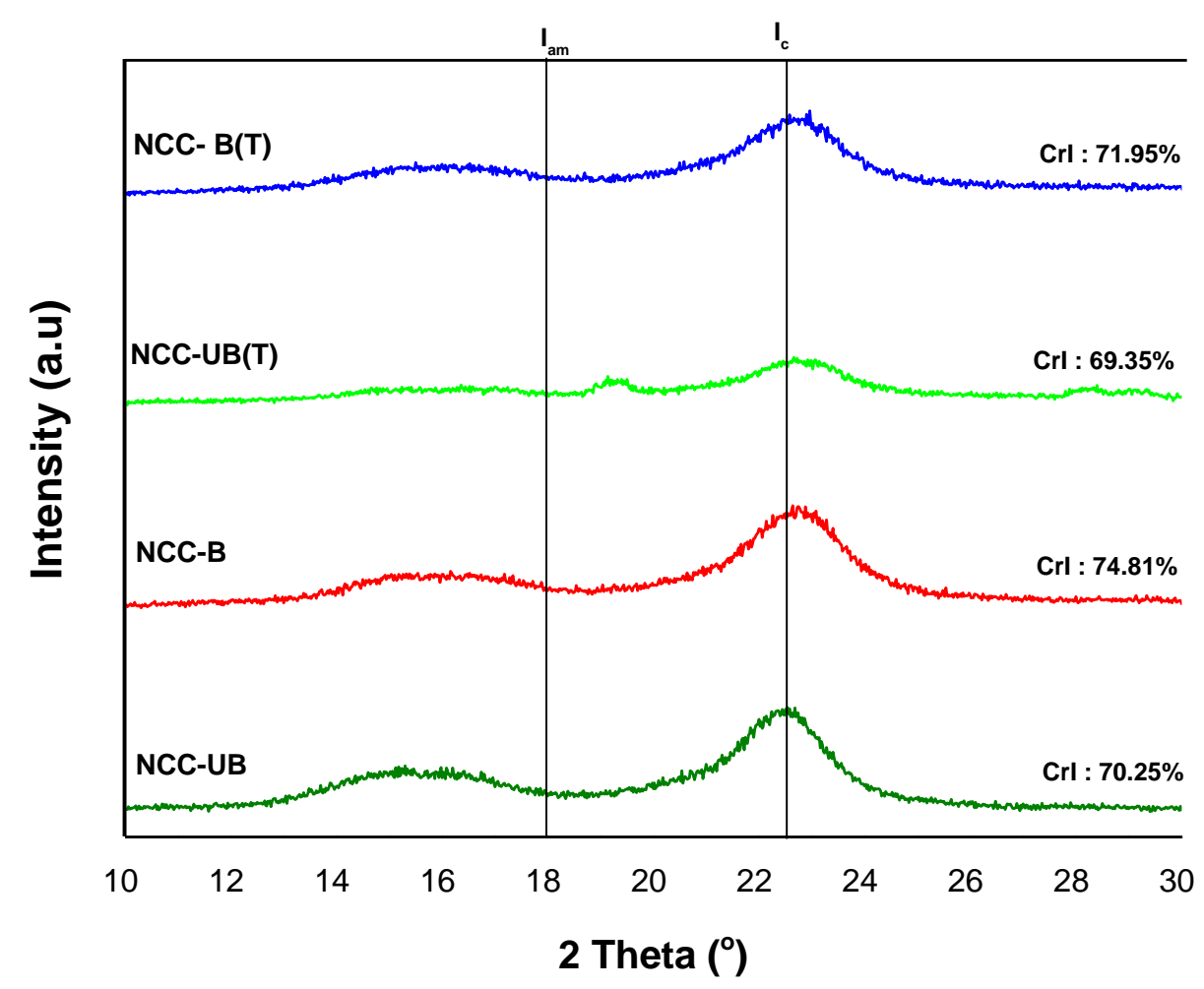

Fig. 2. The XRD peaks for unbleached and bleached NCC before and after post alkaline treatment

\subsection{Thermal Analysis of Nanocrystalline Cellulose (NCC)}

\subsubsection{TGA analysis}

The thermal analysis of NCC before and after post alkaline treatment were depicted in Figure 3(a) and $3(b)$. From the graph, both NCC underwent post alkaline treatment (NCC-UB(T) and NCC-B(T)) showed higher degradation temperature particularly at the second stage of degradation. The degradation was believed corresponded to the degradation of the cellulose part of NCC [11]. The degradation for NCC-UB and NCC-B3 started at 251.5 and $325.1{ }^{\circ} \mathrm{C}$, respectively, whilst NCC- UB (T) and NCC- B3 (T) started later at 411.9 and $363.5{ }^{\circ} \mathrm{C}$, respectively, indicate better thermal stability after being neutralised. This result supports the claimed reported by Rosa et al., [9] stated that the application of strong bases like $\mathrm{NaOH}$ can help to remove the sulphates remainder within NCC and overcome the problem of thermal properties.

Apart from that, NCC-UB (T) shows higher degradation temperature compared to NCC-B (T) which may be corresponded to the amount of lignin that still lingering around to protect the NCC from the degradation process. This finding proves that the residual lignin improves the thermal performance of the NCC persisting up to the end of the degradation process $[9,11]$. The NCC-UB also showed the highest amount of left residue indicates the function of lignin that help to slow down the degradation process up to $700{ }^{\circ} \mathrm{C}$. According to Yang et al., [11] lignin degradation is the most difficult to decompose at very low mass rate. The decomposition usually takes place around $250-900{ }^{\circ} \mathrm{C}$. The activity of chemical bonds in lignin covered an extremely wide range and led to a high temperature of degradation. This behaviour is also due to its three kinds of benzene-propane units, which being heavily cross-linked and having very high molecular weight thus lead to slow degradation process and impart better thermal stability $[11,16]$ 


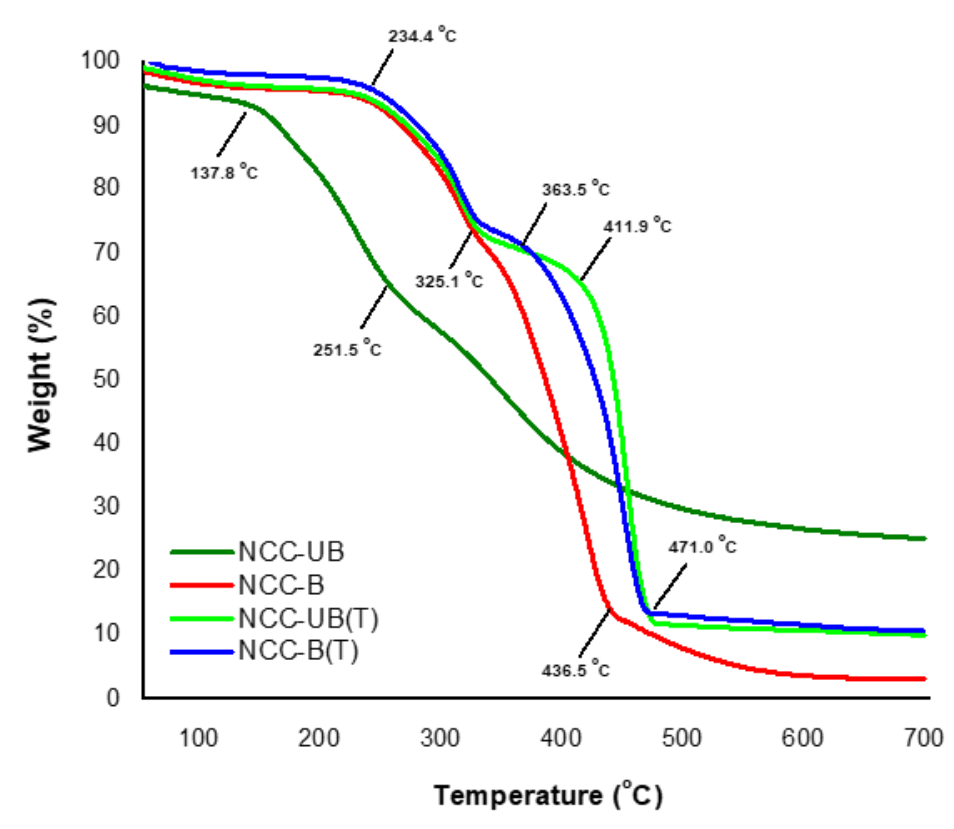

(a)

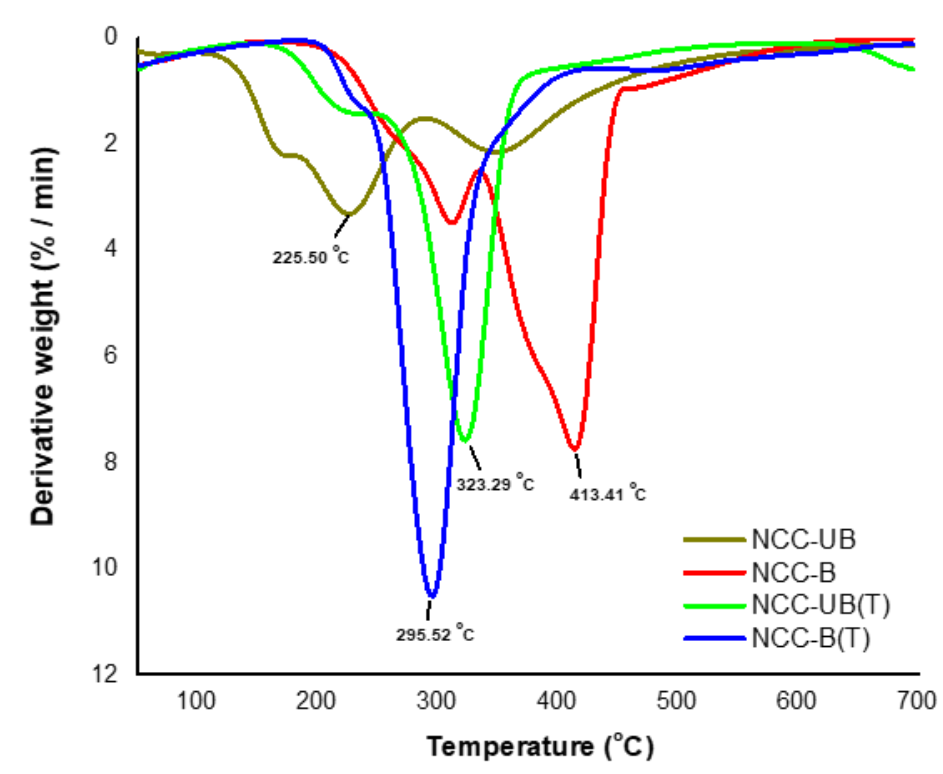

(b)

Fig. 3. The TGA graphs (a) and DTG graphs (b) of NCC before and after post alkaline treatment

The thermal degradation of the NCCs presented in TGA graph were supported with DTG properties as showed in Figure 3(b). It is clearly shown that NCC-UB starts an early degradation at $226{ }^{\circ} \mathrm{C}$ indicates the degradation of amorphous materials. The main degradation of NCC-B occurs later at $413^{\circ} \mathrm{C}$ correspond to the degradation of cellulose part of the NCC. The degradation of NCCUB $(T)$ was observed occurred at later temperature compared to NCC-B $(T)$ may correspond to the function of residual lignin as thermal insulator to protect NCC and improves its thermal stability. 


\subsubsection{DSC analysis}

The DSC properties of the post alkaline treated NCC were listed in Table 3. The first endothermic peaks for all samples fell in the same range around $140{ }^{\circ} \mathrm{C}$. This stage corresponds to the water evaporation of the NCC $[14,19]$. The endothermic peaks for alkaline treated NCCs in phase II were observed to be higher compared to those of the untreated NCCs. The endothermic peaks of NCC-UB increased from 186.26 to $218.29{ }^{\circ} \mathrm{C}$ after the NCC went through the alkaline rinsing process. Meanwhile, two endothermic peaks were depicted for NCC-B (T) at 200.04 and $326.44{ }^{\circ} \mathrm{C}$, which were significantly higher than those of the NCC-B. The results show that the alkaline rinsing affects the removal of remaining sulphate group between NCCs and improved the thermal properties and supported the findings done by Roman and Winter [8] and Rosa et al., [20].

Table 3

The DSC important values for KC and all NCCS

\begin{tabular}{llll}
\hline Sample & \multicolumn{2}{l}{$\begin{array}{l}\text { Endotherms peaks } \\
\left({ }^{\circ} \mathrm{C}\right)\end{array}$} & $\begin{array}{l}\text { Enthalpy, } \Delta \mathrm{H}_{\mathrm{f}} \\
(\mathrm{J} / \mathrm{g})\end{array}$ \\
\cline { 2 - 3 } & Phase I & Phase II & \\
\hline NCC-UB & 143.82 & 186.26 & 213.8 \\
NCC-B & 146.52 & 236.03 & 203.6 \\
NCC-UB(T) & 149.33 & 218.29 & 54.54 \\
NCC-B(T) & 139.58 & 200.04 & 25.49 \\
& & 326.44 & 213.9 \\
\hline
\end{tabular}

\section{Conclusion}

In this work, the remaining lignin in NCC was observed to give some influence to the properties of NCC especially on its thermal stability. Higher lignin content was successfully proved to extend the degradation of the NCC and improves its melting temperature. The post alkaline treatment on both NCC-UB and NCC-B help to remove the remaining sulphate groups which prove the finding on FTIR analysis. The thermal properties of the neutralized NCC were observed to further improve by shifting the degradation temperature and DSC endothermic peaks to higher temperature due to sulphate removal. However, the neutralized NCC were unable to withstand higher degradation temperature by showing low percentage of residue up to $700^{\circ} \mathrm{C}$. Generally, the post alkaline treatment is observed to be unnecessary for unbleached NCC.

\section{Acknowledgement}

This work was supported by the Ministry of Higher Education (KPT) and Higher Institutional Centre of Excellence (HiCOE) Grant 6369109 for the financial support to carry this study.

\section{References}

[1] Sharma, Amita, Manisha Thakur, Munna Bhattacharya, Tamal Mandal, and Saswata Goswami. "Commercial application of cellulose nano-composites-A review." Biotechnology Reports 21 (2019): e00316. https://doi.org/10.1016/i.btre.2019.e00316

[2] Kim, Joo-Hyung, Bong Sup Shim, Heung Soo Kim, Young-Jun Lee, Seung-Ki Min, Daseul Jang, Zafar Abas, and Jaehwan Kim. "Review of nanocellulose for sustainable future materials." International Journal of Precision Engineering and Manufacturing-Green Technology 2, no. 2 (2015): 197-213. https://doi.org/10.1007/s40684-0150024-9

[3] Gibbons, John H. "Technologies for reducing dioxin in the manufacture of bleached wood pulp." (1989). 
[4] Rayung, Marwah, Nor Azowa Ibrahim, Norhazlin Zainuddin, Wan Zuhainis Saad, Nur Inani Abdul Razak, and Buong Woei Chieng. "The effect of fiber bleaching treatment on the properties of poly (lactic acid)/oil palm empty fruit bunch fiber composites." International journal of molecular sciences 15, no. 8 (2014): 14728-14742. https://doi.org/10.3390/ijms150814728

[5] Salas, Carlos, Tiina Nypelö, Carlos Rodriguez-Abreu, Carlos Carrillo, and Orlando J. Rojas. "Nanocellulose properties and applications in colloids and interfaces." Current Opinion in Colloid \& Interface Science 19, no. 5 (2014): $383-$ 396. https://doi.org/10.1016/i.cocis.2014.10.003

[6] Sulaiman, Hanisah Syed, Chi Hoong Chan, Chin Hua Chia, Sarani Zakaria, and S. H. S. Jaafar. "Isolation and fractionation of cellulose nanocrystals from Kenaf core." Sains Malaysiana 44, no. 11 (2015): 1635-1642.

[7] Huang, Siwei, Ling Zhou, Mei-Chun Li, Qinglin Wu, and Dingguo Zhou. "Cellulose nanocrystals (CNCs) from corn stalk: Activation energy analysis." Materials 10, no. 1 (2017): 80. https://doi.org/10.3390/ma10010080

[8] Roman, Maren, and William T. Winter. "Effect of sulfate groups from sulfuric acid hydrolysis on the thermal degradation behavior of bacterial cellulose." Biomacromolecules 5, no. 5 (2004): 1671-1677. https://doi.org/10.1021/bm034519

[9] Rosa, MF, ES Medeiros, JA Malmonge, KS Gregorski, DF Wood, LHC Mattoso, SH Imam. "Cellulose nanowhiskers from coconut husk fibers: Effect of preparation conditions on their thermal and morphological behavior." Carbohydrate Polymers (2010): 83-92. https://doi.org/10.1016/j.carbpol.2010.01.059

[10] Rozman, H. D., K. W. Tan, R. N. Kumar, A. Abubakar, ZA Mohd Ishak, and H. Ismail. "The effect of lignin as a compatibilizer on the physical properties of coconut fiber-polypropylene composites." European polymer journal 36, no. 7 (2000): 1483-1494. https://doi.org/10.1016/S0014-3057(99)00200-1

[11] Yang, Haiping, Rong Yan, Hanping Chen, Dong Ho Lee, and Chuguang Zheng. "Characteristics of hemicellulose, cellulose and lignin pyrolysis." Fuel 86, no. 12-13 (2007): 1781-1788. https://doi.org/10.1016/i.fuel.2006.12.013

[12] Sabaruddin, F. A., and M. T. Paridah. "Effect of lignin on the thermal properties of nanocrystalline prepared from kenaf core." In IOP Conference Series: Materials Science and Engineering, vol. 368, no. 1, p. 012039. IOP Publishing, 2018. https://doi.org/10.1088/1757-899X/368/1/012039

[13] Jonoobi, Mehdi, Jalaludin Harun, Manju Mishra, and Kristiina Oksman. "Chemical composition, crystallinity and thermal degradation of bleached and unbleached kenaf bast (Hibiscus cannabinus) pulp and nanofiber." BioResources 4, no. 2 (2009): 626-639.

[14] Chan, Hoong Chi, Chin Hua Chia, Sarani Zakaria, Ishak Ahmad, and Alain Dufresne. "Production and characterisation of cellulose and nano-crystalline cellulose from kenaf core wood." BioResources 8, no. 1 (2013): 785-794. https://doi.org/10.15376/biores.8.1.785-794

[15] Zaini, Lukmanul Hakim, Mehdi Jonoobi, Paridah Md Tahir, and Samaneh Karimi. "Isolation and characterization of cellulose whiskers from kenaf (Hibiscus cannabinus L.) bast fibers." (2013). https://doi.org/10.4236/jbnb.2013.41006

[16] Poletto, Matheus, Heitor L. Ornaghi, and Ademir J. Zattera. "Native cellulose: structure, characterization and thermal properties." Materials 7, no. 9 (2014): 6105-6119. https://doi.org/10.3390/ma7096105

[17] Kumar, K. Kishor, Dr K. Raj Narender Reddy, and S. Sripathy. "Evaluation OF Flexural and Water Absorption Properties of Short Kenaf Fiber Reinforced Green Composites." Advanced Materials Manufacturing \& Characterization 3, no. 2 (2013): 503-507. https://doi.org/10.11127/ijammc.2013.07.06

[18] Wulandari, W. T., A. Rochliadi, and I. M. Arcana. "Nanocellulose prepared by acid hydrolysis of isolated cellulose from sugarcane bagasse." In IOP conference series: materials science and engineering, vol. 107, no. 1, p. 012045. IOP Publishing, 2016. https://doi.org/10.1088/1757-899X/107/1/012045

[19] Morán, J. I., and V. Alvarez. "a., Cyras, VP, \& Vázquez, A.(2008). Extraction of cellulose and preparation of nanocellulose from sisal fibers." Cellulose 15: 149-159. https://doi.org/10.1007/s10570-007-9145-9

[20] Rosa, Simone ML, Sônia MB Nachtigall, and Carlos A. Ferreira. "Thermal and dynamic-mechanical characterization of rice-husk filled polypropylene composites." Macromolecular Research 17, no. 1 (2009): 8-13. https://doi.org/10.1007/BF03218594 